\title{
As bases do pensamento do filósofo Álvaro Borges Vieira Pinto (1909-1987) e sua atuação no Instituto Superior de Estudos Brasileiros (ISEB)
}

Michelle Fernandes Lima ${ }^{a}$

\section{Resumo}

Este artigo é parte integrante da Pesquisa de Doutorado, intitulada: "Atualidade do pensamento de Álvaro Borges Vieira Pinto (1909-1987) para o debate sobre a reforma universitária". Buscamos explicitar a formação e as bases do pensamento de Álvaro Borges Vieira Pinto, destacando a influência católica e integralista presente no início de sua atuação, bem como suas atividades no Departamento de Filosofia do Instituto Superior de Estudos Brasileiros (ISEB), no período de 1955 a 1961. Nesse período, foi acontecendo seu afastamento dos princípios católicos e integralistas, e a crescente preocupação com a necessidade de um projeto nacional e também de universidade. Destacamos a influência do integralismo e do catolicismo na sua formação, a sua atuação no departamento de Filosofia do ISEB e a sua preocupação com o desenvolvimento nacional.

Palavras-chave: Pensadores brasileiros. Álvaro Borges Vieira Pinto. Estudos brasileiros.

\section{Introdução}

Álvaro Vieira Pinto (1909-1987) foi um importante filósofo brasileiro. Atuou no Instituto Superior de Estudos Brasileiros (ISEB) como Diretor do Departamento de Filosofia, de 1955 a 1961; na última fase de Instituto (1961-1964), assumiu a direção geral dessa instituição. Deixou uma rica produção, ainda pouco conhecida e estudada. Neste artigo, buscamos explicitar o contexto de formação e as bases que marcaram o pensamento de Álvaro Borges Vieira Pinto, a partir de 1955, quando passa a atuar no ISEB, desempenhando importante papel nas discussões

a Universidade Estadual do Centro Oeste - UNICENTRO - Departamento de Pedagogia. Irati, Paraná, Brasil. 
acerca dos rumos da sociedade brasileira. Priorizamos, neste trabalho, as obras Ideologia e desenvolvimento nacional (1956) e Consciência e realidade nacional (1960), publicadas pelo ISEB, bem como estudos que interpretam a obra desse pensador.

Destacamos, neste estudo, a presença das bases católicas e integralistas no início da atuação de Vieira Pinto, no campo da Filosofia e da Política. Essas bases não podem ser consideradas como "marcas indeléveis" no seu pensamento, pois, a partir de 1955, é possível identificar um movimento no seu pensamento, pelo seu afastamento dos princípios católicos e integralistas, e a crescente preocupação com a necessidade de um projeto nacional, em que as massas seriam protagonistas.

\section{As bases católicas e integralistas do pensamento de Vieira Pinto}

Destacamos inicialmente que, para elaboração da trajetória de Vieira Pinto, contamos com a contribuição de duas publicações do educador Dermeval Saviani: um verbete publicado no Dicionário dos Educadores no Brasil, organizado por Maria de Lourdes de Albuquerque Fávero e Jader de Medeiros Brito (1999), e uma entrevista de Vieira Pinto concedida para esse educador em 1981, publicada no livro Sete lições sobre Educação de Jovens e Adultos.

Também a obra Álvaro Vieira Pinto: a personagem histórica e sua trama (1998), escrita por Marcos César Freitas, por oferecer um quadro bem completo sobre a trajetória de nosso autor e especialmente sobre a influência do integralismo e do catolicismo na sua formação, será utilizada com destaque nesse item.

Saviani (1999, p. 47) informa que, na data da entrevista, Vieira Pinto já

[...] se encontrava com a saúde debilitada. A audição e a visão estavam de tal modo enfraquecidas que já não mais permitiam que ele prosseguisse no seu trabalho de escritor. Com o agravamento de seu estado de saúde, veio a falecer no dia 11 de junho de 1987, na Cidade do Rio de Janeiro.

Álvaro Borges Vieira Pinto, filho de Carlos M. Vieira Pinto e Arminda Borges Vieira Pinto, nasceu na cidade de Campos, Rio de Janeiro, no dia 11 de novembro de 1909. Realizou os estudos primários e secundários com os jesuítas, no Colégio 
Santo Inácio do Rio de Janeiro. Ao término desses estudos, decidiu cursar Medicina, mas não foi aceito por não ter idade mínima para a entrada na Universidade. Nesse período, sua família mudou-se para São Paulo e Vieira Pinto ficou um ano sem estar matriculado em curso regular. Saviani $(1999$, p. 45) explica que, apesar disso, esse período foi importante

[...] em termos da sua formação literária e filosófica. Com efeito, corria o ano de 1922 e, estando em São Paulo, pôde ele participar das agitações da Semana de Arte Moderna, travando relações com os intelectuais que encabeçaram aquele movimento cultural. (SAVIANI, 1999, p. 45).

Retornando ao Rio de Janeiro, já com 14 anos de idade, ingressou na Faculdade Nacional de Medicina. Saviani (1999) ressalta as dificuldades financeiras que Viera Pinto enfrentou para concluir seus estudos. Após o término do curso, em 1932, trabalhou por 16 anos num Laboratório de Biologia com pesquisas sobre o câncer e, por conta dessa atividade, aprofundou seus estudos de matemática e física. Ainda segundo Saviani (1999, p. 45):

[...] com o advento da Segunda Grande Guerra, a Cadeira de História da Filosofia ficou vaga em razão da saída de alguns professores alemães. Em conseqüência, Vieira Pinto foi nomeado Professor Substituto de História da Filosofia da então Faculdade Nacional de Filosofia. Para essa nomeação, contribuiu a indicação de seu nome por Alceu Amoroso Lima que levou em conta a recomendação do Padre Leonel Franca para que o ensino de Filosofia no Brasil incorporasse a lógica matemática.

O campo de formação de Vieira Pinto, portanto, é amplo: perpassa as áreas de Medicina, Matemática, Física e Filosofia.

Em 1949, fez uma viagem à França e estudou filosofia durante um ano na Sorbonne. Quando retornou, em 1950, prestou concurso para a Cátedra de História da Filosofia na Faculdade Nacional de Filosofia, para a qual defendeu a tese: Ensaios sobre a dinâmica na cosmologia de Platão, com o que se tornou, em 1951, professor catedrático na Faculdade Nacional de Filosofia, da Universidade do Brasil $1^{1}$. A partir dessa data, se afastou integralmente da medicina e se dedicou aos estudos filosóficos.

\footnotetext{
${ }^{1}$ Fonte dessas informações: Ata da Congregação da Faculdade Nacional de Filosofia, da reunião de 9 de maio de 1950, arquivo: FNFi/PROEDES/UFRJ. Cópia cedida pela professora Maria de Lourdes Albuquerque Fávero.
} 
$\mathrm{Na}$ entrevista concedida ao Professor Dermeval Saviani, em 1981, Vieira Pinto explicou que sua atuação como professor de História da Filosofia tinha: “[...] uma orientação exclusivamente pragmática, quer dizer, dava o curso guiado por manuais da filosofia comum, idealista, mas sempre num nível superior e elevado, desenvolvendo cronologicamente o pensamento dos filósofos" (SAVIANI, 1999, p. 45).

Este autor considera que o exercício do magistério

[...] foi decisivo na conformação de seu próprio pensamento filosófico. Com efeito, a necessidade de ministrar aulas sobre os principais filósofos o levava a estudá-los até conhecê-los profundamente, a ponto de assumir a lógica interna das filosofias de que se assenhoreava. Compreende-se, assim, a sua adesão ao platonismo coroada com a tese concluída em 1950, a sua passagem pelo kantismo e pelo idealismo alemão, de modo geral, e depois, pelo existencialismo. (SAVIANI, 1999, p. 45).

Sobre sua atuação política, registra-se que, em 1934, Vieira Pinto ingressou na Ação Integralista Brasileira (AIB). Em relação à influência das bases integralistas na sua formação, Freitas (1998) afirma que Vieira Pinto

[...] em 8 de outubro de 1934 matriculou-se na província n.1985 da Ação Integralista Brasileira. Naquela ocasião, ainda marcado pela efervescência da Semana e atraído pela mobilização crescente em torno da AIB, aproximou-se da questão social sob o impacto do tema "identidade nacional". Naquele contexto iniciou-se em uma teorização sociopolítica que seria recuperada anos mais tarde na troca do ofício de médico com o de professor de História da Filosofia.

Torna-se importante indagar por que o integralismo atraiu Vieira Pinto e outros intelectuais.

Bertonha (2000, p. 59) explica que as transformações ocorridas no Brasil na década de 1920, aliadas à ideia de criar um pensamento "genuinamente nacional", contagiaram a intelectualidade brasileira. $\mathrm{O}$ autor destaca que a forma de pensar esse nacionalismo e a vontade de mudança variou muito. 
Plínio Salgado (1895-1975) representa uma das formas com que o "nacionalismo" foi interpretado. Escritor e jornalista, foi um dos grandes "expoentes do modernismo" em São Paulo. As suas produções e pesquisas, a viagem para Europa para o estudo da literatura política e, especialmente, a sua passagem pela Itália, onde pode conhecer o fascismo, o estimularam, na volta ao Brasil, a ajudar na organização da "Legião Revolucionária de São Paulo". Mais tarde, afastado da Legião por conflitos com a liderança, fundou a "Sociedade de Estudos Políticos", em 1932. Dessa associação, informa Bertonha (2000), surgiu a Ação Integralista Brasileira (AIB), em outubro de 1932.

Vieira Pinto, nesse período, estava em São Paulo e teve contato com as ideias integralistas.

Em 1934, a AIB, segundo Bertonha (2000, p. 64), tomou realmente corpo e tornouse uma organização semimilitar, com milícia armada e exaltação à obediência dos membros a seus superiores, especialmente ao chefe nacional Plínio Salgado, que tinha como proposta a defesa da nacionalidade, a ordem, a disciplina e a organização corporativa e hierárquica dos brasileiros em um Estado integral.

A AIB, na visão de Cruz (2011, p. 197), pode ser considerada como um

[...] dos principais atores sociais no contexto da modernidade brasileira nos anos 30 . A sua relevância está no fato de ter sido o primeiro partido de massas do Brasil, com cerca de 500.000 adeptos, e de seu discurso e sua proposta de organização do Estado e da sociedade terem atingido simpatizantes em vários grupos sociais.

O discurso desse movimento atraía, pelo caráter de modernidade que apresentava; no entanto, sem abrir mão dos elementos tradicionais como os valores cristãos. Cruz (2011) analisa o discurso do movimento integralista e aponta a presença do diálogo entre modernidade e antimodernidade. Nas palavras da autora, essa proposta, que atraiu um número expressivo de adeptos, pode ser entendida como:

Um dos movimentos políticos e sociais que, no esteio da modernidade, reage às conseqüências negativas da própria modernidade, defendendo propostas de organização social que visem estancar o processo moderno de fragmentação, insegurança e instabilidade. Para tanto, usa um discurso próximo ao elaborado 
por vários movimentos reacionários e antimodernos, com críticas à razão, ao materialismo, ao individualismo burguês e ao cosmopolitismo. No entanto, os elementos antimodernos e a própria crítica da modernidade são reelaborados e ganham novo significado para dar vazão a uma proposta de sociedade em que a própria utopia moderna de ordem e controle seja recuperada [...]. (CRUZ, 2011, p. 197-198).

Esse movimento criticava os problemas gerados pela sociedade moderna, sem considerar, na visão de Cruz (2011, p. 203), a luta de classes. O caminho para resolver os problemas sociais partiria da utilização dos valores cristãos, como: "[...] solidariedade, piedade e amor ao próximo, e a edificação de um Estado forte que agregasse todos os grupos sociais harmonicamente".

Outro elemento destacado por Cruz (2011) refere-se ao nacionalismo. Esse foi um elemento de destaque no pensamento de Vieira Pinto, como veremos na obra Ideologia e Desenvolvimento Nacional, obra resultado de uma aula inaugural realizada no ISEB. O nacionalismo, na perspectiva integralista, partia da defesa de valores modernos, como igualdade e liberdade, e da ideia de um Estado com uma organização hierárquica, soberano e acima das classes.

Não cabe aqui um estudo detalhado sobre o integralismo, mas sim observar que esse movimento marcou a formação inicial de Vieira Pinto e possibilitou sua entrada na carreira acadêmica. É importante pontuar que essa proposta atraiu o pensador e muitos outros intelectuais pelo seu discurso “[...] conservador moderno, como a defesa de um Estado forte, capaz de harmonizar corporativamente os corpos sociais" (CRUZ, 2011, p. 212).

Vieira Pinto, como se viu, começou sua carreira acadêmica por indicação de Alceu Amoroso Lima, a partir de um pedido do Padre Leonel Franca, na Faculdade Nacional de Filosofia (FNFi), como professor da cadeira de História da Filosofia. Portanto, o catolicismo e o integralismo contribuíram para a entrada de Vieira no meio acadêmico.

A criação da FNFi, por meio da Lei n. ${ }^{\circ} 452$ de 05/07/1937, foi fruto da desmontagem da Universidade do Distrito Federal (UDF), criada em 1935.

A UDF foi extinta pelo Decreto n. ${ }^{\circ} 1063$, de 20 de janeiro de 1939. Seus cursos foram transferidos para a Universidade do Brasil. 
Vieira Pinto, por pertencer ao grupo integralista, fez parte do novo quadro que compôs a FNFi. A organização da Faculdade Nacional de Filosofia se dá mediante o Decreto-Lei n. ${ }^{\circ} 1190$, de 4 de abril de 1939, que dispõe, no art. 1. ${ }^{\circ}$ : "A Faculdade Nacional de Filosofia, Ciências e Letras, instituída pelo Decreto n. ${ }^{\circ} 452 / 37$, passa a denominar-se Faculdade Nacional de Filosofia".

A atuação de Vieira Pinto, na concepção de Freitas (1998, p. 51): “[...] teve pouco brilho, mas serve para ilustrar a singularidade do seu procedimento cognitivo. Vieira Pinto estudou conforme as demandas programáticas da cadeira que dirigia". A sua entrada na FNFi despertou o interesse de Roland Corbisier, que o convidou para atuar no ISEB em 1955, como Diretor do Departamento de Filosofia, assunto do nosso próximo item.

Freitas (1998, p. 52) reitera que o catolicismo "[...] não deve ser tomado como uma marca indelével na história pessoal de Vieira Pinto [...] Em poucos anos, o professor Álvaro 'desviaria' do roteiro suposto por seus 'padrinhos"', pois, a partir de 1961, na terceira e última fase do ISEB (1961-64), é possível perceber um novo movimento no pensamento de Vieira Pinto. Sua aproximação em relação ao marxismo é evidente e também sua participação na discussão sobre as reformas de base, especialmente a universitária.

A entrada de Vieira Pinto no ISEB marca o início do seu afastamento em relação aos preceitos católicos e integralistas. A publicação da obra Ideologia e desenvolvimento nacional, resultado de uma aula inaugural em 1956, pode ser considerada como registro desse processo.

Como argumento inicial da obra, o autor caracterizou a ingenuidade da análise até então realizada sobre o nosso país e considerou que é preciso romper com o silêncio das massas. Isso se deu pela ausência da filosofia e de uma " [...] concepção universalizadora em nossa incipiente consciência converteu-se, por sua vez, em um dos fatores de opacidade da nossa visão de nós mesmos, e, consequentemente também, de retardamento do progresso" (1960a, p. 12).

O papel do "povo" é muito evidenciado na obra citada. Vieira Pinto criticou o caráter de "incultas" que se atribuiu às massas e considerou que estas possuem uma "consciência potencial em expectativa", uma vez que as massas, na visão desse autor, começaram a reivindicar e pressionar as classes dirigentes por mudanças nas condições de vida. Essas reivindicações “[...] exprimem a desconformidade 
entre a representação consciente que as massas fazem do seu estado vital e as condições econômicas e sociais do meio onde habitam" (PINTO, 1960a, p. 33).

A partir dessa crítica e das demais ideias apresentadas na obra, é possível observar o afastamento do autor em relação às ideias integralistas. A defesa dos valores cristãos e a harmonia dos grupos sociais são elementos não contemplados na sua análise. A ideia de um Estado forte capaz de congregar as classes, presente no integralismo, não foi defendida por Vieira. O pensador defendeu que cabe ao poder público assumir a direção do projeto de desenvolvimento do país. No entanto, não desconsiderou a necessidade do consentimento e da participação das massas no processo de desenvolvimento nacional.

Freitas (1998) considera que, em 1956, a Igreja Católica inicia um processo de "secularização" e o pensamento de Vieira Pinto, nesse mesmo período, passa por um processo de "laicização", ou seja, pela defesa dos aspectos leigos e pelo afastamento dos preceitos religiosos. Na análise de Freitas (1998, p. 73):

Grosso modo, pode-se dizer que a partir de 1956, enquanto Vieira Pinto laicizou-se, a Igreja Católica brasileira secularizouse ainda mais, reorganizando seu espaço político e utilizando argumentos contrários aos dos chamados laicistas que, em geral, eram todos os defensores de instituições públicas, universais e gratuitas como a escola, por exemplo.

A ideia de laicização é marcante na obra Ideologia e desenvolvimento nacional. Um dos aspectos dessa questão refere-se ao debate "escola pública $v s$. privada". As críticas dos católicos em relação ao ISEB e, especialmente a Vieira Pinto e outros integrantes de formação integralista católica, ganharam corpo a partir da publicação dessa obra, em 1956.

Vieira Pinto defendia uma ordem pública, distanciando-se de alguns setores da Igreja Católica que "[...] cobravam do Estado e do Legislativo um conveniente entendimento sobre o papel das instituições privadas na organização da vida social". Essa foi uma das discussões que permearam o debate da LDB 4024, de 1961.

A Campanha em defesa da Escola Pública foi organizada, em 1960, sob a liderança de Júlio Mesquita Filho, dono do jornal O Estado de São Paulo. Porém, a lei de 1961 foi aprovada com mais de 200 emendas e frustrou os que lutavam pela prioridade da escola pública. 
Na concepção de Freitas (1998), as teses defendidas em 1956 por Vieira Pinto demonstravam a radicalidade a respeito da função do Estado no processo de desenvolvimento industrial do país e o caráter nacionalista do desenvolvimento apregoado por ele, demarcando assim seu afastamento do "quadro católico".

As bases integralistas e católicas do pensamento de Vieira Pinto, como pontuamos nesse item, marcaram sua entrada no meio acadêmico e no ISEB; no entanto, é possível observar uma mudança nas suas ideias a partir de 1955, quando passou a defender um projeto de desenvolvimento nacional e o protagonismo das massas nesse processo, aspectos não coerentes com o movimento integralista e a igreja.

No próximo item, nos dedicamos à atuação de Vieira Pinto no Departamento de Filosofia do ISEB de 1955 a 1961, demarcando o contexto e a obra desse período.

\section{3 Álvaro Vieira Pinto no Departamento de Filosofia do Instituto Superior de Estudos Brasileiros (1955 a 1961)}

Neste item, demarcamos o contexto de produção das ideias de Vieira Pinto e sua atuação nas duas primeiras fases do ISEB, denominadas por Toledo (1994) como "teorizante" e "nacional-desenvolvimentista", respectivamente.

Considerando-se que Álvaro Vieira Pinto é um homem do seu tempo, que participou de questões polêmicas no âmbito da política, da economia e da educação no Brasil, é fundamental caracterizar o contexto brasileiro das décadas de 1950 e 1960 para localizar a produção e a ação desse importante filósofo brasileiro, no período de 1955 a 1961.

O período de 1946 a 1964 é caracterizado pelo término do Estado Novo e o início da chamada "redemocratização do país". Os reflexos dos resultados da Guerra interferiram diretamente no cenário político e econômico do Brasil, e dos demais países da América Latina.

Nilo Odália (1981, p. 354) analisa a situação do Brasil e o contexto internacional, e considera que o fim da guerra "[...] foi o sinal para que se deflagrassem as lutas de libertação, causando novas brechas no antes monolítico sistema colonial europeu, repercutindo intensamente na política-internacional". O autor explica que a luta pela libertação nacional marcou quase todos os continentes em que 
o colonialismo se fez presente e traz como característica a "reformulação do conceito de nacionalismo"3. Sobre essa reformulação, Almeida (1993) considera que grande parte das pesquisas sobre o "caráter do nacionalismo populista" apresenta limitações, como a não apreensão da contradição do nacionalismo populista brasileiro, por não considerar as diferentes variantes desse nacionalismo e a dificuldade de uma "linguagem comum" para uma "interlocução coerente do tema".

A ideia de libertação também ganha destaque no pós-guerra (1945). Na visão de Odália (1981), esta não se reduz à liberdade política, mas à busca de ultrapassar o papel de consumidores de produtos industrializados e de fornecedores de matérias-primas. $\mathrm{O}$ foco das atenções passa a ser "a formulação dos problemas que envolviam o desligamento das bases metropolitanas".

A temática sobre o desenvolvimento do nosso país estava inserida numa discussão maior que envolveu outros países, também da América Latina, e se apresentou com uma das principais problemáticas na obra de Vieira Pinto. Freitas (2006) considera a influência de pressupostos da Comissão Econômica para América Latina (CEPAL) nos escritos mais "densos" de Vieira Pinto. O autor assim explica:

[...] tanto nos escritos cepalinos quanto nos escritos de Vieira Pinto, a dicotomia centro/periferia oferece condições para uma compreensão singular do impacto da propagação do incremento tecnológico e da utilização da técnica para a substituição de trabalho manual. [...] $\mathrm{Na}$ acepção de Vieira Pinto, o centro capturava para si um dos significados da tecnologia e ideologicamente o proclamava como universal, reservando ao mundo da periferia a condição de paciente receptor das inovações técnicas, quando, na verdade, já se pronunciava uma "fase histórica" na qual já era possível atuar como "agente propulsor" do próprio desenvolvimento, sem aguardar as demandas do capital externo (FREITAS, 2006, p. 83).

O segundo governo de Vargas, iniciado em 1950, apresentou uma política de industrialização voltada para o nacionalismo. Alencar (1996, p. 358) considera que o nacionalismo varguista tinha duas facetas:

[...] era, por um lado, uma estratégia de política econômica que não rompia inteiramente a dependência com relação ao capital 
internacional e imperialista; por outro lado, tratava-se de uma ideologia elaborada e imposta pelos grupos que controlavam o Estado e que procurava associar os interesses burgueses com os interesses de todo o povo brasileiro, como se fosse, em todos os aspectos, uma coisa só.

O governo seguinte, iniciado em 1956, com Juscelino Kubitschek, instalou no Brasil uma ideia de modernização. Segundo Neves (1997), este período, também denominado de "Anos Dourados", foi um momento de intensas movimentações dos partidos políticos, das ligas camponesas, da União Nacional dos Estudantes e dos sindicatos. Intelectuais da época, como Álvaro Vieira Pinto, mostravam grande preocupação com o desenvolvimento do país e defendiam ideias nacionalistas. Foi neste contexto de luta pelo desenvolvimento nacional que o ISEB foi criado, em 1955 no Governo Café Filho (1954-1955). Suas origens datam de 1952, a partir das atividades de alguns intelectuais que formavam o "Grupo Itatiaia"2. Desse grupo, nasceu o Instituto Brasileiro de Economia, Sociologia e Política (IBESP), responsável pela publicação dos Cadernos Novos $\operatorname{Tempos}^{3}$, que marcaram a produção intelectual de 1950 (NEVES, 1997).

As atividades realizadas no Grupo Itatiaia geraram a necessidade de institucionalizar e sistematizar os estudos, por meio de um centro de caráter contínuo. Em 1953, havia sido criado o IBESP que funcionou de 1953 a 1955. As ações foram organizadas por meio de conferências, cursos e publicações.

A institucionalização do ISEB ocorreu em 1955, no governo Café Filho, por meio do Decreto n. ${ }^{0} 37.608$ de 14 de julho:

art.2- O ISEB tem por finalidade o estudo, o ensino e a divulgação das ciências sociais, notadamente da sociologia, da história, da economia e da política, especialmente para fim de aplicar as categorias e os dados dessas ciências à análise e à compreensão crítica da realidade brasileira, visando à elaboração

\footnotetext{
2 "Do Rio, iam Cândido Mendes, Guerreiro Ramos, Oscar Lorenzo Fernandez, Israel Klabin, Ignácio Rangel, José Ribeiro Lira, Cleantho de Paiva Leite, Cid Carvalho, Fábio Breves, Ottolmy Strauch, Heitor Lima Rocha, além de eu próprio. De São Paulo, iam Roland Corbisier, Vicente Ferreira da Silva, Ângelo Arruda, Almeida Salles, Paulo Edmur de Souza Queiroz e José Luiz de Almeida Nogueira Porto" (JAGUARIBE, 1979, p. 95).

3 "O IBESP tinha uma revista de que eu era diretor - Cadernos do Nosso Tempo -, da qual foi possível tirar cinco números. Mas chegou um ponto em que não havia condições de se manter esse esforço financeiro, que dependia exclusivamente da parte de meus proventos como advogado, e decidimos que a única forma de dar continuidade à iniciativa era converter o IBESP em Instituição Pública" (JAGUARIBE, 2005, p. 33).
} 
de instrumentos teóricos que permitam o incentivo e a promoção do desenvolvimento nacional (BRASIL, 1959, p. 316).

É importante apreender que o ISEB foi criado como um órgão subordinado ao Ministério da Educação e Cultura (MEC); no entanto, possuía "autonomia e plena liberdade de pesquisa, opinião e cátedra” (TOLEDO, 1978, p. 33).

Jaguaribe (1979, p. 95) explica que os estudos e discussões realizados no Grupo Itatiaia objetivavam compreender o contexto da época e sua relação com as especificidades econômicas, políticas e culturais do Brasil. A posição dos integrantes era muito heterogênea. $\mathrm{O}$ autor pontua que os paulistas, grupo do qual ele fazia parte, se colocavam numa perspectiva ligada à direita, com base no integralismo, e os cariocas "tinham posições tendencialmente de esquerda". O ISEB, segundo as normativas do decreto, era dirigido por um Conselho Curador ${ }^{4}$, que denominava o diretor executivo. Quanto ao financiamento, o Instituto recebia, segundo informações de Jaguaribe (1979), uma verba de seis mil contos por ano.

Álvaro Vieira Pinto atuava nesse período como Chefe do Departamento de Filosofia e não recebia remuneração pelas suas atividades. Nelson Werneck Sodré, membro do grupo, desde o início das atividades, informa que as primeiras atividades estavam centradas na formulação da "ideologia do desenvolvimento". Sobre essa questão, Sodré (1977) explica que essa tarefa estava longe de uma efetivação, pois isso dependeria, na visão do autor, de um "mínimo de homogeneidade de pensamento" e, naquela fase inicial, as diferenças teóricas entre os integrantes eram "enormes". Um exemplo apresentado pelo autor foi a organização da obra Introdução aos problemas brasileiros, de 1955. Não se tinha, no entendimento de Sodré, uma formulação econômica e política que pudesse definir uma proposta comum. Essa heterogeneidade não esteve presente somente nas formulações iniciais, mas era uma característica da estrutura do ISEB.

Por sua vez, Caio Navarro Toledo (1978) examinou produções teóricas do ISEB. Sua obra é citada e comentada em diversos trabalhos, e podemos dizer que se tornou um estudo indispensável para o estudo do ISEB. Esse autor (1978, p.31), explica que a criação do ISEB está relacionada com a necessidade do Estado de dispor de agências que "racionalizassem o surto de desenvolvimento do país". Sobre a ideologia elaborada pelo ISEB, Toledo (1978, p. 37) apresenta, com

\footnotetext{
${ }^{4} \mathrm{O}$ primeiro conselho curador era formado pelos seguintes integrantes: Anísio Teixeira, Ernesto Luiz de Oliveira Júnior, Hélio Burgo Cabal, Hélio Jaguaribe, José Augusto de Macedo Soares, Nelson Wernek Sodré, Roberto Campos e Roland Corbisier (JAGUARIBE, 1979).
} 
destaque, as produções de Vieira Pinto, e considera que, nestas, "[...] a noção de autenticidade - freqüentemente identificada como a de veracidade - desempenhará um papel fundamental".

Vieira Pinto publicou sua primeira obra no Instituto, em 1956, resultado de uma aula inaugural. A dependência do Brasil em relação aos países estrangeiros e a necessidade de um projeto nacional incomodavam muito esse pensador. Nessa obra, Ideologia e desenvolvimento nacional, podemos identificar essa preocupação. Demonstra que o Brasil, na segunda metade do século XX, estava naquele momento com características "peculiares e inéditas". Isso se deu porque, na sua concepção, a dependência que marcou o processo de formação do Brasil não permitia uma visão clara sobre a realidade. Considera que havia uma "opacidade da nossa visão de nós mesmos e, consequentemente, também do retardamento do progresso" (PINTO, 1960a, p. 12). Aponta duas causas para essa questão:

[...] por não estarmos então capacitados para perceber o fenômeno “desenvolvimento" em sua verdadeira significação, e por não podermos dar-lhe os benefícios de incentivo e intensificação que a visão correta e objetiva dos fatos propiciaria (PINTO, 1960a, p. 12).

Vieira Pinto considera, ainda, que faltou no nosso passado intelectual a presença da filosofia, ou seja, um instrumental conceitual indispensável para a compreensão da realidade brasileira. Um outro aspecto de argumentação do autor é o aumento da população brasileira:

[...] esse fenômeno de aumento da população brasileira parecenos o dado fundamental, porque nos coloca em face desta encruzilhada: ou tomamos o rumo do desenvolvimento, o que se dará à medida que formos capazes de utilizar os dados da ciência e os instrumentos da técnica, a serviço de uma ideologia do progresso, ou, se o não fizermos, enveredarmos pela estrada do pauperismo, que nos conduzirá à condição das grandes massas asiáticas. Partimos, pois, deste dado absolutamente primordial: que o Brasil é, antes de tudo, um corpo em crescimento (PINTO, 1960a, p. 15). 
O papel das massas no processo de desenvolvimento nacional é marcante na obra Ideologia e desenvolvimento nacional. $\mathrm{O}$ autor não aceita a ideia de que as massas são "incultas". Compreende que:

[...] quando o processo do desenvolvimento nacional, em todos os setores, dá a indivíduos existentes no seio da massa a oportunidade de superação, ocorre a súbita tomada de consciência da sua situação e, através dela, da realidade brasileira em geral. Esse indivíduo converte-se de ser meramente sensitivo, figurante mudo do drama social, no qual só tinha atuação mecânica, em ser expressivo, em centro de forças vivas, em exigência consciente. Fazendo o descobrimento da própria voz, o homem do povo vai utilizá-la naturalmente para exprimir a miséria da sua condição e reclamar contra ela (PINTO, 1960a, p. 18).

É importante dizer que alguns conceitos, como, por exemplo, o de "massa", ganham contornos inéditos no pensamento de Vieira Pinto. Esses contornos demonstram a necessidade de não homogeneizar as produções do ISEB. Martini (2008, p. 5) explica que, para Vieira, as massas deveriam "falar através da voz do estudioso da realidade", ideia que se aproxima da concepção da função de intelectuais orgânicos da classe trabalhadora, em Gramsci.

Martini (2008, p. 12), ao tratar da questão das "massas" em Vieira Pinto, explica que esse pensador considera "a participação das massas imprescindível para um projeto de país que deveria se lançar ao desenvolvimento".

A defesa do desenvolvimento nacional é tônica principal da obra Ideologia e desenvolvimento nacional, bem como a ação das massas nesse movimento. Vieira Pinto, nesse primeiro período, defendeu um projeto nacionalista. Na sua percepção, o conhecimento da situação nacional é fundamental para a elaboração do melhor projeto possível do futuro, parte da compreensão de que o desenvolvimento nacional é um processo, entendido como uma "[...] sucessão de aspectos, algo que admite sem dúvida descrição empírica em termos de justaposição cronológica" (PINTO, 1960a, p. 22). Partindo desse ponto de vista, o desenvolvimento nacional, na concepção de Vieira Pinto, implica em considerar as demais categorias do processo: finalidade, unidade, especificidade e ideia diretriz. Isso quer dizer que, sem a consciência prévia sobre uma representação da realidade, não é possível elaborar um plano de desenvolvimento. Nesta linha de pensamento, o autor declarou sua tese: "Sem ideologia do desenvolvimento não há desenvolvimento 
nacional" (PINTO, 1960a, p. 29). Essa ideologia deve ser necessariamente um fenômeno das massas e tem de proceder da sua consciência.

[...] a constituição da ideologia é, portanto, acontecimento social que depende estritamente do número de indivíduos em cuja consciência se instale a idéia. O processo de desenvolvimento está, pois em função direta do esclarecimento da consciência popular, ou seja, tem velocidade proporcional ao número de indivíduos nos quais se efetua a transmutação qualitativa que os conduz do estado de consciência privada ao de consciência pública (PINTO, 1960a, p. 31-32).

Vieira Pinto questiona de que maneira ocorrerá o progresso da ideologia na consciência nacional e aponta a educação das massas como um dos aspectos dessa questão. Defende a necessidade de criar um novo conceito de educação, como parte do projeto nacional. Uma teoria que, segundo ele, possa delinear a formação de um homem capaz de realizar o desenvolvimento do país. Nas palavras do autor, a reforma da educação

[...] terá de ser profunda. Consistirá, antes de tudo, em substituir os quadros educacionais inspirados no humanismo hoje sem sentido, por outros que, ao contrário do que muitos pensam, não serão anti-humanistas, e muito menos anti-humanos, mas simplesmente representativos de nova concepção de humanismo. Deverá ser abandonada a preocupação de formar doutores e exegetas de coisas mortas [...] Apresenta-se, assim, a educação como aspecto capital da teoria do desenvolvimento. Para o Brasil atual, a educação é a difusão dessa ideologia (PINTO, 1960a, p. 44).

Constamos que, desde aquele tempo e ainda hoje, a discussão sobre as reformas educacionais é um tema em pauta, pois a educação pública, embora seja apontada como "algo primordial" nos discursos governamentais e na mídia, apresentase, no Brasil, com grande escassez de recursos e seu sucateamento é notório e preocupante.

Vieira Pinto deixa claro, na obra aqui analisada, que a tarefa do ISEB é contribuir para a elaboração da ideologia do desenvolvimento nacional, que atenda aos anseios das massas. Na época de sua publicação, o Brasil era governado por 
Juscelino Kubitschek de Oliveira, cujo período de expansão capitalista, alicerçado em torno do capital estrangeiro e em investimento estatal, como afirma Gorender (1997, p. 111), foi de significativa crise econômica, política e social.

O ISEB, nesse contexto, segundo explica Jaguaribe (1979), estava numa segunda fase (1959 a 1960), sob a direção de Roland Corbisier. As ações do grupo foram marcadas em três planos: da teoria geral, dos estudos brasileiros e da práxis política. No que se refere à teoria geral, buscavam a superação do que eles chamavam de limitações "histórico-sociológicas do positivismo e do marxismo", com o objetivo de pensar uma concepção que orientasse para a compreensão da realidade brasileira. Observamos uma ênfase ao nacionalismo. Assim, no que tange aos estudos brasileiros, o ISEB tinha o intuito de criar os fundamentos de uma política de desenvolvimento nacional. A práxis política, mencionada por Jaguaribe (1979), caracteriza-se pela realização do projeto de desenvolvimento nacional, fundamentado nos princípios do nacionalismo desenvolvimentista.

Havia no ISEB uma tendência de superação do positivismo e do marxismo, sobre a qual Jaguaribe $(1979$, p. 97) informa que o grupo, que a almejava, era representado por: Guerreiro Ramos, Roland Corbisier, Álvaro Vieira Pinto, Candido Mendes e Ewaldo Correia Lima. O autor afirma que esses pensadores buscavam o entendimento da realidade brasileira que pudesse oferecer caminhos para um desenvolvimento nacional, eixo central dos propósitos do ISEB. Numa perspectiva diversa, segundo Jaguaribe (1979, p. 97), Nelson Werneck Sodré "era um historiador de assentadas convicções marxistas".

Sobre a atuação do ISEB, vale mencionar as críticas por parte dos católicos em relação aos cursos e publicações desse instituto. Brás de Alcântara e Antônio Carlos Vilaça publicaram na Revista Católica de Cultura, em 1959, dois textos, sendo, respectivamente: ISEB, Comunista? e I.S.E.B. Nos dois textos, os autores mencionados denunciam a "infiltração comunista" e a difusão do marxismo e da doutrina vermelha na maioria dos cursos ministrados.

Vilaça (1959, p. 943) explicita que, pela atmosfera desses cursos, o ISEB pode ser visto como "um clube de marxistas". Um dado importante que esse autor apresenta refere-se à sua estranheza em relação aos professores católicos desse instituto, e afirma:

[...] não entendo como um católico possa participar de um tal ambiente. Para que não me faltasse o contacto direto ou a 
experiência pessoal, fui várias vezes a conferências no auditório do ISEB e guardo como católico a mais penosa impressão. Não apenas se ensina ali o materialismo, como já criou um clima de agressividade em relação ao espiritualismo e, particularmente, ao catolicismo.

Fica evidente, pela leitura desses textos, o rompimento de membros do ISEB com o catolicismo. Vieira Pinto é um exemplo, como já afirmamos no item anterior.

Nessa segunda fase do ISEB, Vieira Pinto finalizou o livro Consciência e realidade nacional, de grande impacto para a filosofia brasileira. Obra de dois volumes, publicada em 1960, representou a perspectiva política debatida no ISEB. Apresenta temas polêmicos, que causaram elogios e muitas críticas, com base em: concepção de trabalho, consciência crítica e ingênua, e realidade nacional. Na introdução do livro, Vieira Pinto retomou uma ideia já apresentada em 1956 na obra Ideologia e desenvolvimento nacional, sobre a afirmação de que a sociedade brasileira "[...] atingiu uma etapa do seu processo em que está se produzindo profunda alteração na sua consciência" (PINTO, 1960b, p. 1). O objetivo da obra foi o do esclarecimento sobre a origem e as formas de consciência da realidade nacional.

Esse pensador continuou preocupado com a formação de consciência e defendeu a necessidade de as massas reconhecerem sua situação num país subdesenvolvido. Vieira Pinto deixa claro que o estudo não é "matéria de dissertação acadêmica", mas uma análise da nossa própria situação pessoal. Explica que a obra se apresenta como "meditação livre" e visa a contribuir para o "[...] esforço do desenvolvimento nacional, ao procurar apreciar os reflexos na consciência social das transformações em andamento" (PINTO, 1960b, p. 17). No primeiro volume, trata das diferentes interfaces que envolvem a questão da consciência, tais como: a sociedade, a consciência ideológica e o desenvolvimento, a consciência ocupada, as consciências ingênua e crítica, a consciência política e o desenvolvimento, e a consciência de massa. Na sequência do primeiro volume, o pensador prioriza a análise da consciência ingênua e os diferentes aspectos que decorrem desse conceito.

Dentre as diferentes formas de compreensão da realidade nacional, Vieira Pinto defende a necessidade de uma análise filosófica da realidade, por parte dos pensadores que tenham condições para tal tarefa, que Gramsci chama de "intelectuais". Nosso autor, por outro lado, define que a consciência “[...] é sempre um conjunto de representações, ideias, conceitos, organizados em estruturas suficientemente 
caracterizadas para se distinguirem tipos ou modalidades" (PINTO, 1960b, p. 20). Explica a consciência ingênua como aquela que "[...] apenas reflete sobre o mundo das suas ideias, o investiga, enriquece pela observação, pelo estudo, pela meditação, mas não inclui entre essas ideias a representação dos fatores objetivos de que elas dependem, ou mesmo nega enfaticamente tal dependência" (PINTO, 1960b, p. 20). A consciência crítica é concebida como aquela que "[...] conhece a existência do necessário condicionamento das ideias que possui, busca relacioná-las aos seus suportes reais e, sem deixar de organizar logicamente a sua compreensão, não exclui a referência obrigatória a um fundamento na objetividade" (PINTO, 1960b, p. 20).

No segundo volume de sua obra, Vieira Pinto se dedica à sistematização da consciência crítica e às categorias: objetividade, historicidade, racionalidade, totalidade, atividade, liberdade, nacionalidade e princípios de uma política nacionalista. Fica evidente, assim como na obra de $1956^{5}$, sua preocupação com o desenvolvimento do país e, mais do que isso, com a elaboração de um projeto nacional. Assim como os demais pensadores do ISEB, Vieira Pinto defendia a ideia de que o Brasil, no final da década de 1950 e no início da década de 1960, começou a ser analisado a partir de novos modelos de pensamento. Em suas palavras (PINTO, 1960b, p. 11-12):

[...] há indubitavelmente uma nova consciência em ascensão no seio da sociedade brasileira, mas, não sendo ainda dominante, luta para se definir a si própria e refutar os modos de pensar precedentes. Vivemos um período em que diferentes configurações de idéias, representando cada qual um modo de compreensão da realidade, combatem pelo direito de serem reconhecidas como legítimas e de assumirem a direção política do processo nacional.

Essas ideias ajudam na compreensão da posição tomada na questão da universidade, pois esse autor vai defender uma reforma que não se limita às questões institucionais, mas explicita a necessidade de grandes mudanças sociais.

Álvaro Vieira Pinto retoma, na obra em foco, a defesa do desenvolvimento como processo e unidade, uma tese, já apresentada em 1956, de que "[...] não há projeto social sem ideologia de massa, ou seja, sem suficiente unificação do pensamento e da vontade popular mediante uma representação objetiva da realidade e a decisão de modificá-la" (PINTO, 1960b, p. 33).

${ }^{5}$ Ideologia e desenvolvimento nacional. 
Sobre o subdesenvolvimento, ele afirma que:

[...] é uma contradição histórica: a marcha do processo universal faz-se na direção que tende a aboli-lo. Mas, enquanto o país se encontra em luta para suprimi-lo, apresenta-se como a contradição suprema, aquela que afeta todos os aspectos da realidade nacional e, por conseguinte, constitui a base objetiva da consciência que o país toma dele próprio (PINTO, 1960b, p. 37).

O impacto da obra Consciência e realidade nacional foi grande. Destacamos aqui a interpretação de alguns autores que se dedicaram a leitura e interpretação dessa obra: Rodrigo (1988), Toledo (2007, 1978), Freitas (1998), Cortes (2003), Lebrun (2005) e Konder (1962).

Lídia Maria Rodrigo, em O nacionalismo no pensamento filosófico: aventuras e desventuras da filosofia no Brasil (1988), investiga a forma como o projeto nacionalista se traduz no âmbito filosófico. Prioriza o estudo da obra Consciência e realidade nacional de Vieira Pinto e elege, como tema central de sua leitura, a preocupação com a elaboração de um pensamento filosófico original e autônomo. Examina o estudo que esse pensador realizou sobre as correntes filosóficas europeias: lógica formal, ecletismo, fenomenologia existencial e pensamento dialético. Aponta que Vieira Pinto assume posições diversas em relação a estas. As duas primeiras, na visão da autora, são rejeitadas pelo autor e as demais são aceitas, mas submetidas à assimilação crítica.

Rodrigo (1988) considera que Vieira Pinto elege o subdesenvolvimento como contradição principal do país. Dessa maneira, coloca o motivo do atraso da nação na dependência em relação aos países desenvolvidos. A solução seria a industrialização. O imperialismo, segundo Vieira Pinto, atinge a nação com um todo. Com isso, ganha visibilidade uma ideologia nacional, que é defendida por esse pensador e pelos demais membros do ISEB.

Vale destacar que as posições de esquerda, como explica Rodrigo (1988), seja no ISEB ou fora dele, como o combate ao imperialismo e a defesa de um desenvolvimento nacional autônomo, representavam uma fase necessária para se chegar ao socialismo. No entanto, essa posição é criticada por essa autora, por não "sair da órbita desse sistema". 
Toledo (2007), por sua vez, aponta que Vieira Pinto buscou, na obra Consciência e Realidade Nacional, sintetizar os resultados de diferentes análises sobre a formação social brasileira, contribuindo para a formulação de uma ideologia de desenvolvimento nacional. Esse autor considera que havia, na obra, "[...] uma dominância de cunho existencial: poder-se-ia afirmar que a perspectiva existencial desempenharia o papel de 'fio condutor' em todo o pensamento filosófico isebiano" (TOLEDO, 2007, p. 313).

Essa observação sobre a presença de categorias existencialistas na obra de Vieira Pinto não desconsidera os diversos alertas desse autor, na obra, sobre as insuficiências das concepções existencialistas. Toledo (2007) entende que a defesa da história e da dialética feita por Vieira Pinto indica sua aproximação com o marxismo, mais do que qualquer outra corrente teórica. Considera também a "simpatia" de Vieira Pinto em relação ao pensamento de Lukács. Nas palavras de Toledo (2007, p. 315): "[...] a aproximação com a visão lukacsiana, presente em História e Consciência de Classe, estaria no privilégio que Vieira Pinto concede às massas trabalhadoras, no desvendamento e na transformação da sociedade subdesenvolvida".

Na obra Consciência e Realidade Nacional, o autor trata do conceito de trabalho, apontando a dimensão existencial, representada pela categoria amanualidade. A partir da filosofia da existência, Pinto (1960b, p. 69) afirma que:

[...] viram os teóricos daquela corrente que o mundo se apresenta ao existente humano como espaço de ações possíveis mediante objetos dispostos ao seu redor, a serem tomados como utensílios, e que, portanto, a determinação mais imediata dos entes é a de se darem como algo que "está à mão", caráter esse que foi chamado de "amanualidade". Com efeito, a objetividade se faz acessível ao homem mediante a amanualidade com que se apresentam a nós os entes circunstantes preexistentes à ação.

Segundo Freitas (1998), Vieira Pinto não abandona esse conceito ao longo de sua produção teórica. Para ele, a dimensão da amanualidade seria "via real" de acesso à realidade. Toledo (2007, p. 315), por sua vez, acredita que Vieira Pinto "[...] associava-se a todo um movimento de reinterpretação da obra de Marx, que tem nas suas obras de juventude sua referência fundamental". Conceitos como luta de classes, valor-trabalho e mais-valia estão ausentes na obra Consciência e Realidade Nacional, como afirma Toledo (2007), o que também pudemos constatar. 
Rodrigo (1988) destaca, ainda, que a ideologia defendida por Vieira Pinto e outros pensadores do ISEB atingiu amplos setores da esquerda brasileira, como o Partido Comunista Brasileiro e a União Nacional dos Estudantes.

Gerard Lebrun (2005), em artigo publicado - "A realidade nacional e seus equívocos”, em 1962 - analisa a obra Consciência e realidade nacional e considera que o livro se apresenta como "fenomenologias da consciência de país subdesenvolvido". Dentre as diversas críticas apresentadas por Lebrun (2005, p. 175), destacamos as seguintes: concepção ambígua de nacionalismo; "o que marca uma etapa necessária de estratégia revolucionária"; subordinação da ciência à ideologia, e ecletismo presente na argumentação do autor.

Mesmo diante dessas críticas, Lebrun (2005, p.199-200) reconhece que:

Vieira Pinto escreveu um livro interessante e significativo, mas, a meu ver, muitíssimo contestável do ponto de vista teórico. Sei que o autor tem razão de repetir que os problemas brasileiros exigem soluções urgentes, e não apenas tagarelices 'filosóficas' ou 'tecnocráticas'. Tem razão ao atacar todas as formas de neocolonialismo. Tem razão ao sustentar que o desenvolvimento acelerado da indústria nacional é condição indispensável para a liberdade efetiva do Brasil. Tem razão ainda ao insistir na necessidade de um reagrupamento nacionalista no imediato (como ele mesmo sublinha).

Norma Côrtes (2003) também realizou uma leitura de Vieira Pinto, no trabalho intitulado "Esperança e Democracia: as ideias de Álvaro Vieira Pinto". Diferentemente de autores citados, Côrtes (2003, p. 21) considera que "[...] tanto à direita como à esquerda, a obra de Álvaro Vieira Pinto conheceu poucos adeptos ou entusiastas". A autora defende a necessidade de ler as obras desse autor, pois, na sua compreensão, ele

[...] não chegou a conhecer, nem em vida, nem postumamente, a consagração. Se sua reputação não foi depreciada como mera vulgaridade filosófica, ele também não provou dos bons frutos da fala. Quando lembradas - salvo raras exceções -, as ideias de Vieira sempre aparecem junto a predicados pouco lisonjeiros ou debochados (CÔRTES, 2003, p. 26). 
Essa autora problematiza as interpretações a respeito da obra de Vieira Pinto, em especial o livro Consciência e realidade nacional, e afirma que: "[...] durante mais de duas décadas, seu pensamento foi sistematicamente combatido pela geração de pensadores sociais e políticos que compuseram, instalaram e montaram a atual estrutura institucional acadêmica e universitária" (CÔRTES, 2003, p. 27).

Entretanto, as diferentes leituras realizadas sobre a produção de Vieira Pinto apontam que ainda há muito a pesquisar, pois sua obra é rica e pode oferecer importantes elementos de análise para a história do Brasil e também sobre educação e universidade. Cortês (2003) afirma que seu estudo sobre Vieira Pinto:

[...] está inconcluso. Ele consiste apenas numa interpretação e, portanto, não pretendo oferecer termo de solução para aquilo que apresenta. A rigor, nele não há exatamente algo a se concluir. Porque, de certa forma, seu desfecho é uma espécie de convite - o convite para que voltemos a ler as obras de Álvaro Vieira Pinto.

Como observa Norma Côrtes, o estilo do texto de Vieira pode ser lido como um convite à meditação filosófica:

As características de estilo de Consciência e realidade nacional alteravam a própria experiência de leitura da obra. A singeleza expositiva franqueava aos leitores indiscriminalmente, a possibilidade de realizarem um exercício filosófico. Na medida em que era acessível a todos, a leitura de CRN se assemelhava a uma espécie de diálogo cujo início reclama apenas pela espontaneidade da consciência ingênua, mas que paulatinamente vai se transformando na lenta aquisição da consciência crítica (CÔRTES, 2003, p. 78).

Leandro Konder (1962, p. 504) também analisa a obra Consciência e realidade nacional e, ao contrário, a considera de "[...] extraordinária importância, destinada, sem dúvida, a exercer salutar influência sobre o movimento de emancipação nacional - de cujo avanço ela própria é uma conseqüência". Esse autor explica que as formulações de Vieira Pinto tinham caráter "participante" pela própria natureza dos aspectos analisados na obra e que esse pensador foi criticado, mas pelos círculos "[...] conservadores e retrógrados da sociedade brasileira, a serviço do imperialismo". 
Konder (1962) explica que Vieira Pinto estudou, na obra em foco, as relações entre a realidade nacional e as ideologias, a partir do "primado da objetividade"; analisou os problemas brasileiros e apontou o subdesenvolvimento como algo a ser superado. O desenvolvimento a ser conquistado não é entendido por Álvaro como um processo mecânico: ele supõe a ação dos homens. Konder (1962, p. 506) aprecia a compreensão de Vieira no que se refere à relação entre o "determinismo dialético histórico e a liberdade humana", pois a "consciência não é livre senão quando é ativa, quando se constitui em instrumento de intervenção da realidade".

A luta contra o imperialismo é marcante na obra de Vieira Pinto. Sobre esta, Konder (1962, p. 506) questiona qual seria o papel da burguesia nacional, na perspectiva desse pensador. Trata-se de uma questão "delicada" na visão de Konder, especialmente porque Vieira Pinto atuava no ISEB, órgão criado com o objetivo de "[...] contribuir para a revolução nacional, mas em proveito da burguesia nacional. É precisamente o Estado burguês brasileiro que mantém o ISEB”. Konder (1962, p. 506) questiona como Vieira Pinto poderia examinar essa questão de forma independente.

É nesse ponto que Vieira Pinto revela ser um verdadeiro homem de ciência, pois chega a se libertar das limitações que lhe adviriam de uma consciência de classe burguesa e da filiação oficial do ISEB para assumir algumas posições que escapam ao esquema das conveniências da burguesia como classe.

Konder (1962) diverge de Vieira Pinto por ele não dar o devido valor à contradição interna, entre as classes. Na percepção desse autor (1962, p. 507), "Vieira Pinto é levado a crer numa unidade de objetivos entre o proletariado e a burguesia nacional que ultrapassa os estritos limites da luta contra o imperialismo e seus aliados internos".

Esse autor chama atenção para os interesses diversos dos trabalhadores e da burguesia nacional: para os primeiros, o desenvolvimento é uma "questão vital e não um mero interesse". Mesmo apontando essa divergência, Konder (1962, p. 508) explica que suas observações referem-se "mais ao que ele deixou de dizer do que ao que ele disse". O autor também destaca a riqueza e a profundidade da obra Consciência e realidade nacional. 


\section{Apontamentos finais}

Neste estudo, foi possível observar o movimento das ideias de Vieira Pinto. Na base de sua formação e início da sua trajetória acadêmica, o integralismo e o catolicismo fundamentaram seu pensamento. A sua entrada no ISEB, em 1955, marca seu afastamento em relação a esses fundamentos, como vimos no primeiro item. Um exemplo disso, é que os cursos e professores do ISEB passam a ser criticados pelos católicos e considerados por eles como "comunistas", "marxistas", especialmente pelas discussões acerca do imperialismo.

Nessa fase, Vieira Pinto passou, como informa Saviani (1999, p. 46), “[...] a combinar o magistério universitário de História da Filosofia com as novas funções exercidas no ISEB, a sua orientação filosófica atingiu a maturidade e ganhou outra densidade".

O foco central das produções de Vieira Pinto no período de 1955 a 1961 é caracterizado pela preocupação com a elaboração de um projeto nacional, de cujo processo as massas seriam protagonistas. As obras Ideologia e desenvolvimento nacional e Consciência e realidade nacional publicadas nesse período explicitam sua inquietação em compreender a realidade nacional. Nesse processo, segundo Saviani (1999, p. 46), Vieira Pinto terminou por assumir "[...] a perspectiva da filosofia dialética, em termos técnico-filosóficos ancorada em Hegel, através de uma terminologia extraída do existencialismo, mas sociologicamente inspirada no marxismo".

Já a partir de 1961, na terceira e última fase do ISEB (1961-64), é possível perceber um novo movimento no pensamento de Vieira Pinto. Sua aproximação em relação ao marxismo é evidente e também sua participação na discussão sobre as reformas de base, especialmente a universitária.

O debate teórico e ideológico nas décadas de 1950 e 1960 foi intenso e marca a produção intelectual de Vieira Pinto e sua atuação no ISEB. É claro que não podemos colocar como sinônimas as concepções defendidas por Vieira Pinto e pelo ISEB, pois, como já afirmamos, essa instituição não se constitui pela homogeneidade de linhas teóricas e, ainda ao longo de sua existência, passou por diferentes fases.

De fato, pela leitura das obras de Vieira Pinto até 1964, observamos claramente o destaque do protagonismo das massas, mas não identificamos como isso aconteceria. 
Somente constatamos a preocupação com a formação de uma consciência crítica. As bases esquerdistas da produção de Vieira Pinto são evidentes nas suas obras e em sua atuação como Diretor do ISEB, a partir de 1961.

Vieira Pinto foi personagem muito atuante no movimento de Reforma Universitária apoiando a proposta radical, uma das três propostas de reforma que surgiram nesse período. A sua posição de apoio em relação à proposta radical de reforma universitária fica explícita em seu livro A questão da universidade (1962), publicado pela União Nacional dos Estudantes (UNE), em que Álvaro Vieira Pinto imprime sua opinião a respeito da universidade e da sua reforma. Para Vieira Pinto, a reforma era algo mais complexo do que um simples reordenamento institucional, estava ligada a uma transformação da estrutura universitária que possibilitasse o acesso da classe não dominante ao campo da cultura presente no cenário universitário.

O que ganhou grande destaque e pode ser considerada uma preocupação fundamental nas obras de Vieira Pinto nesse período é o desenvolvimentismo, que seria dirigido pelas massas trabalhadoras, deixando a ideia de revolução em nome do nacionalismo, defendido não só por ele, mas por outras frentes da esquerda brasileira.

Com o fechamento do ISEB, em 1964, pelo governo militar, Vieira Pinto prossegue seus estudos em obras, como Ciência e Existência (1969), El pensamiento critico en demografia (1973) e Sete lições sobre a educação de jovens e adultos (1982). Duas obras foram publicadas após sua morte a partir do esforço de pesquisadores da área: Sociologia dos países subdesenvolvidos e Conceito de tecnologia volumes 1 e 2 . Esse período pode ser considerado o segundo da sua produção, devido às novas condições em que suas análises são realizadas.

De 1946 a 1964, as obras de Vieira Pinto podem ser caracterizadas pelo caráter de intervenção na realidade brasileira, com propostas estratégicas. A sua atuação no ISEB possibilitou a sua participação em diversos debates, não somente no âmbito das discussões teóricas, mas no delineamento de ações e projetos para o país.

A visão filosófica de Vieira Pinto influenciou o debate sobre a reforma da universidade na década de 1960 e o símbolo dessa influência foi a sua obra $A$ Questão da Universidade (1962); sobre o livro, Álvaro Vieira Pinto afirma, em entrevista dada ao Professor Demerval Saviani (1985), que "[...] aquele livro foi uma conferência que fiz em Belo Horizonte e depois a diretoria da antiga UNE 
me pediu para publicar" (PINTO, 1985, p. 20). Na visão de Veiga (1982), após 1962, a União Nacional dos Estudantes (UNE) passa a defender uma proposta mais radical para as universidades; uma influência que marcou essa posição crítica em relação aos rumos da universidade foi a publicação do livro "[...] tanto na orientação filosófica do movimento, quanto na definição das principais estratégias de ação utilizadas", como concorda Nicolato (1986, p. 31). Cunha (2007, p. 186-187) também considera que a “[...] extinção dos exames vestibulares e a condenação da autonomia universitária, naquelas circunstâncias, eram pontos defendidos por Álvaro Vieira Pinto [...]”, que influenciou a posição dos estudantes.

Vieira Pinto defendeu que a reorganização da educação superior no Brasil passava pela reforma dos conteúdos de classe da universidade, considerando que não se tratava de "reformá-la" ou "mudá-la de forma". Sua luta e posição política não eram pela reforma e sim pelo seu "reconteúdo", que pudesse permitir às "massas" o ingresso no domínio da cultura, a serviço dos seus próprios interesses.

Em meio às diversas reivindicações para as universidades, o governo militar, por meio do decreto $n .^{\circ} 62.937$, de 1968 , instituiu o grupo de trabalho da reforma universitária, composto de 11 membros, com o objetivo de "[...] estudar a reforma da universidade brasileira, visando a sua eficiência, modernização, flexibilidade administrativa e formação de recursos humanos de alto nível para o desenvolvimento do país" (BRASIL, 1968). O grupo deveria apresentar em 30 dias um relatório que alcançasse tal objetivo.

Com isso, podemos perceber que muito embora esta proposta radical tenha ocupado o cenário das discussões sobre a reforma universitária, podemos verificar que a ação do governo, por meio da promulgação da lei 5540/68 atendeu aos anseios do grupo hegemônico, adaptando assim a universidade às necessidades impostas pelo capital na década de 1960. A proposta de Vieira Pinto, juntamente com os estudantes, para a universidade brasileira, tinha como a ação central a defesa da elaboração de um projeto dos estudantes para reforma, pois, desta forma, seria constituir um grupo de pressão social, ou seja, uma unidade das forças estudantis que aliasse a reforma universitária com as demais reformas da sociedade (bancária, agrária, urbana).

O autor também apresenta ações necessárias para tal mudança, como: cogoverno, entendido como instâncias decisórias (departamentos, conselhos, direções etc.); "supressão da trincheira do vestibular"; universidade a serviço das massas, e luta contra a vitaliciedade da cátedra. 
Vieira Pinto define que o objetivo da reforma universitária

[...] é identificar a Universidade com a sociedade brasileira, no seu esforço de desenvolvimento material e espiritual, criando e semeando a cultura, a fim de que esta, juntamente com a liberdade, venham a tornar-se os bens mais preciosos possuídos por todo o homem do povo (PINTO, 1962, p. 163).

Entendemos que a luta para democratização da universidade ainda persiste nos dias atuais. Muito embora, em termos quantitativos ${ }^{6}$, podemos observar uma ampliação, na essência, a universidade ainda atende, principalmente, aos anseios e necessidades da classe dominante. Um dado importante a ser considerado é que ainda temos um número expressivo de analfabetos no Brasil: 12,9 milhões ${ }^{7}$. Vieira Pinto, em 1962, já afirmava que no Brasil a universidade "tem de ser dos ainda analfabetos, do contrário não é do país" (PINTO, 1962, p. 159). Ele alerta que essa defesa deixará de ser utópica quando

[...] a universidade tiver consciência de sua dependência das massas trabalhadoras, não se julgando apenas uma elite santificada $[. .$.$] compreenderá que a ela pertencem não apenas$ os 'alunos que estudam', mas os milhões de 'alunos que não estudam', e por ora não tem nem sequer esperança de um dia estudar (PINTO, 1962, p. 160).

O movimento pela reforma universitária na década de 1960 ocorreu de maneira distinta, em relação à reforma atual, que, como vimos, é caracterizada por inúmeras leis e projetos isolados que alteraram a forma da universidade, mas não seu conteúdo. Sobre esse aspecto, Vieira Pinto apresentou significativas reflexões.

\footnotetext{
${ }^{6}$ Segundo dados do censo de 2011, do Instituto Nacional de Estudos e Pesquisas Anísio Teixeira (INEP), as instituições de educação superior totalizam 2.365, das quais são 190 universidades, 131 centros universitários, 2.004 faculdades e 40 institutos federais e centros federais de educação tecnológica (IFPR/CEFET). Dessas instituições, $88 \%$ são privadas e $12 \%$ públicas (4,75\% estaduais, $4,3 \%$ federais e $3 \%$ municipais). Segundo o Censo, 5.746 .762 alunos estão matriculados no ensino presencial e 992.927, na educação a distância. Os números demonstram que, no período 2010-2011, a matrícula em cursos de graduação nas universidades cresceu 7,9\% na rede pública e 4,8\% na rede privada. Desses, 95\% (6,7 milhões) cursam a graduação: 1,7 milhão em universidades e instituições públicas de ensino e 5 milhões, em universidades privadas.

7 Fonte: http://economia.uol.com.br/noticias/valor-online/2013/09/27/analfabetismo-no-brasil-cresce-em2012-aponta-ibge.htm. Data de acesso: setembro de 2013. Dados do Instituto Brasileiro de Geografia e Estatística (IBGE).
} 


\section{Referências}

ALENCAR, C. et al. História da sociedade brasileira. Rio de Janeiro: Ao Livro Técnico, 1996.

ALMEIDA, L. F. R. O nacionalismo popular e a crise do populismo no início dos anos 60. In: SIMPÓSIO NACIONAL DE HISTÓRIA ANPUH, 17., 1993, São Paulo. Anais... São Paulo: USP, 1993. Disponível em: <http://www.pucsp. br/neils/downloads/v11_12_lucio.pdf $>$. Acesso em: dia jul. 2013.

BERTONHA, J. F. Fascismo, nazismo, integralismo. São Paulo: Ática, 2000.

BRASIL. Ministério da Educação e Cultura - MEC. Departamento Nacional de Educação. Decreto n ${ }^{0} 37.608$, de 14 de Julho de 1955. In: FUNDOS e campanhas educacionais: coletânea de atos oficiais. 1959. v. 1.

. Lei n. 5.540, de 28 de novembro de 1968. Fixa as normas de organização e funcionamento do ensino superior e sua articulação com a escola média. In: CARVALHO, G. I. Ensino superior: legislação e jurisprudência. Rio de Janeiro: Instituto Nacional de Estudos Pedagógicos, 1968. v. 1, p. 83.

CÔRTES, N. Esperança e democracia: as idéias de Álvaro Vieira Pinto. Belo Horizonte: Editora UFMG; Rio de Janeiro: IUPERJ, 2003.

CRUZ, N. R. O diálogo entre o moderno e o antimoderno no discurso da Ação Integralista Brasileira. Revista Estudos Ibero-Americanos, Rio Grande do Sul, v. 37, n. 2, p. 196-214, 2011.

CUNHA, L. A. Universidade Crítica: o ensino superior na república populista. São Paulo: Editora Unesp, 2007.

FÁVERO, M. L. A.; BRITTO, J. M. Dicionário de educadores no Brasil. Rio de Janeiro: Editora UFRJ/MEC: Inep, 1999.

FREITAS, M. C. Álvaro Vieira Pinto: a personagem histórica e sua trama. São Paulo: Cortez, 1998.

. Economia e educação: a contribuição de Álvaro Vieira Pinto para o estudo histórico da tecnologia. Revista Brasileira de Educação, Rio de Janeiro, v. 11, n. 31, p. 80-95, 2006. http://dx.doi.org/10.1590/S1413-24782006000100007 
GORENDER, J. Era o golpe de 64 inevitável?. In: TOLEDO, C. N. (Org.). 1964: visões críticas do golpe: democracia e reformas no populismo. São Paulo: Ed. Unicamp, 1997. p. 112.

JAGUARIBE, H. ISEB: um breve depoimento e uma reapreciação critica. Cadernos de Opinião, Rio de Janeiro, v. 14, p. 94-110, 1979.

. O ISEB e o desenvolvimento nacional. In: TOLEDO, C. N. (Org.). Intelectuais e politica no Brasil: a experiência do ISEB. Rio de Janeiro: Revan, 2005.

KONDER, L. Consciência e realidade nacional: Álvaro Vieira Pinto. Estudos Sociais, Rio de Janeiro, v. 12, p. 504-509, 1962.

LEBRUN, G. A "realidade nacional” e seus equívocos. In: TOLEDO, C. N. (Org.). Intelectuais e politica no Brasil: a experiência do ISEB. Rio de Janeiro: Revan, 2005.

MARTINI, R. Álvaro Vieira Pinto: massas, nacionalismo e cultura na realidade social. 2008. 180 f. Tese (Doutorado em Sociologia)-Universidade Estadual Paulista Júlio de Mesquita Filho, Araraquara, 2008.

NEVES, L. A. Trabalhadores na crise do populismo: utopia e reformismo. In: TOLEDO, C. N. (Org.). 1964 Visões críticas do golpe: democracia e reformas no populismo. São Paulo: Ed. Unicamp, 1997

NICOLATO, M. A. A caminho da lei 5.540/68: a participação dos diferentes atores na definição da reforma universitária. 1986. 519 f. Dissertação (Mestrado em Educação) - Departamento de Educação, Universidade Federal de Minas Gerais, Belo Horizonte, 1986.

ODÁLIA, N. O Brasil nas relações internacionais. In: MOTA, C. G. (Org.). Brasil em perspectiva. São Paulo: Difusão Editorial, 1981.

PINTO, Á. B. V. Ideologia e desenvolvimento nacional. Rio de Janeiro: ISEB, 1960a.

Consciência e realidade nacional: a consciência crítica. Rio de Janeiro: ISEB, 1960b. v. 2. 
. A questão da Universidade. Editora Universitária, 1962.

. Sete lições sobre educação de adultos. São Paulo: Cortez, 1985.

RODRIGO, L. M. O nacionalismo no pensamento filosófico: aventuras e desventuras da filosofia no Brasil. Petrópolis: Vozes, 1988.

SAVIANI, D. Verbete: Álvaro Borges Vieira Pinto. In: FÁVERO, M. L. A.; BRITTO, J. M. Dicionário de educadores no Brasil. Rio de Janeiro: Editora UFRJ/MEC: Inep, 1999.

SODRÉ, N. W. História do ISEB. Temas de Ciências Humanas, São Paulo, v. $1,1977$.

TOLEDO, C. N. A modernidade democrática da esquerda: adeus à revolução? Crítica Marxista, São Carlos, v. 1, n. 1, 1994, p. 27-37

. Intelectuais do ISEB, Esquerda e Marxismo. In: MORAES, J. Q. (Org.). História do Marxismo no Brasil: teorias e interpretações. Campinas: Ed. Unicamp, 2007.

. ISEB: Fábrica de Ideologias. São Paulo: Ática, 1978.

VEIGA, L. Os projetos educativos como projetos de classe: estado e universidade no Brasil (1954-1964). Revista Educação e Sociedade, Campinas, v. 5, n. 11, p. 25-71, 1982.

VILAÇA, A. C. I.S.E.B. Revista Vozes, São Paulo, n. 53, dez. 1959.

\section{The bases of the thought of the philosopher Álvaro Borges Vieira Pinto (1909-1987) and his performance in the Superior Institute of Brazilian Studies \\ Abstract}

This article is a constituent part of a doctoral dissertation entitled "The topicality of the thought of Álvaro Borges Vieira Pinto (1909-1937) to the debate on the university reform". We sought to explain the formation and bases of Álvaro Borges Vieira Pinto's thought, highlighting the catholic and integralist influence present 
in the beginning of his performance, as well as his activities in the Philosophy Department of the Superior Institute of Brazilian Studies (ISEB) between 1955 and 1961. During this period, the philosopher gradually departed from the catholic and integralist principles and became concerned with the necessity of a national project, as well as of a project for the university. We highlight the influence of Integralism (a fascist-based movement occurred in Brazil in the 1930s) and Catholicism in his formation, his performance in the philosophy department of the ISEB, and his preoccupation with the national development. Keywords: Brazilian thinkers. Álvaro Borges Vieira Pinto. Brazilian studies.

\section{Las bases del pensamiento del filósofo Álvaro Borges Vieira Pinto (1909-1987) y su actuación en el Instituto Superior de Estudios Brasileños (ISEB) Resumen}

Este articulo es parte de una investigación doctoral titulada: "Actualidad del pensamiento de Álvaro Vieira Pinto Borges (1909-1987) para el debate sobre la reforma universitaria." Tratamos de explicar la formación y las bases del pensamiento de Álvaro Borges Vieira Pinto, destacando la influencia católica y fundamentalista presente al inicio de sus actividades, así como sus actividades en el Departamento de Filosofía del Instituto de Estudios Brasileños (ISEB) en el periodo de 1955 a 1961. En este periodo ocurre su alejamiento de los principios católicos y fundamentalistas y la creciente preocupación con la necesidad de un proyecto nacional y también universitario. Destacamos la influencia del fundamentalismo y del catolicismo en su formación, su desempeño en el Departamento de Filosofía del ISEB y su preocupación con el desarrollo nacional. Palabras-clave: Pensadores brasileños. Álvaro Borges Vieira Pinto. Estudios brasileños

\section{Informações do autor}

Michelle Fernandes Lima: Professora Adjunta. Doutora em Educação. Contato: mfernandeslima@yahoo.com.br 